\title{
ARISING TECHNICAL ISSUES IN THE DEVELOPMENT OF A TRANSPORTATION AND STORAGE SYSTEM OF SPENT NUCLEAR FUEL IN KOREA
}

\author{
JEONG-HYOUN YOON ${ }^{1}$, WOO-SEOK CHOI ${ }^{2}$, SANGHOON LEE ${ }^{2}$, and KI-SEOG SEO ${ }^{2}$ \\ ${ }^{1}$ Korea Radioactive Waste Management Corporation \\ ${ }^{2}$ Korea Atomic Energy Research Institute \\ Daedeok-daero 1045, Yuseong-gu, Daejeon \\ ${ }^{*}$ Corresponding author. E-mail : wschoi@kaeri.re.kr
}

Received October 20, 2011

In Korea, although the concept of dry storage system for PWR spent fuels first emerged in the early 1990s, wet storage inside nuclear reactor buildings remains the dominant storage paradigm. Furthermore, as the amount of discharged fuel from nuclear power plants increases, nuclear power plants are confronted with the problem of meeting storage capacity demand. Various measures have been taken to resolve this problem. Dry storage systems along with transportation of spent fuel either on-site or off-site are regarded as the most feasible measure. In order to develop dry storage and transportation system safety analyses, development of design techniques, full scale performance tests, and research on key material degradation should be conducted. This paper deals with two topics, structural analysis methodology to assess cumulative damage to transportation packages and the effects of an aircraft engine crash on a dual purpose cask. These newly emerging issues are selected from among the many technical issues related to the development of transportation and storage systems of spent fuels. In the design process, appropriate analytical methods, procedures, and tools are used in conjunction with a suitably selected test procedure and assumptions such as jet engine simulation for postulated design events and a beyond design basis accident.

KEYWORDS : Spent (Nuclear) Fuel, Transportation, Dry Storage, Cumulative Impact, Aircraft Crash

\section{INTRODUCTION}

One of the most critical issues in the nuclear industry is spent nuclear fuel management. The current situation requires an economical and compact storage system that can safely house overflowing spent nuclear fuels from nuclear power plants. However, the fuel management situation in Korean operating nuclear power plants has been exacerbated by implementation of higher burnup with high enrichment to increase economy. As such, it has become more difficult to manage the back-end nuclear fuel cycle including storage of used fuels. There are many challenging design issues related to the development of transportation and storage of spent fuels. The major design issues for such development include radiation shielding analyses, fuel safety verification, thermal evaluations, structure and impact analyses including seismic safety and containment analyses, along with radiation protection, confinement of radionuclides, and service life verification of main component materials. These analyses must be followed by accident evaluations to ensure that radiological consequences due to off-normal and accident events during transferring and storage of spent fuels are acceptably low. As the importance of safety is increasingly emphasized, there is a demand to demonstrate the integrity of storage and transportation systems of spent fuel under circumstances even beyond design basis accidents such as an aircraft crash. This paper introduces two topics, a structural analysis methodology to assess cumulative damage on transportation packages and the effects of an aircraft engine crash on a dual purpose cask. These newly emerging issues are selected from among the many technical issues related to the development of transportation and storage of spent fuels.

Those two issues have been chosen to establish an integrated evaluation methodology to verify the integrity of a new transportation and storage system for spent nuclear fuel and to demonstrate its implementation for fuel management. It can also be regarded as the first attempt to find a solution for the lack of storage capacity of overflowing spent nuclear fuel with the introduction of a Korean transportation and storage system. 

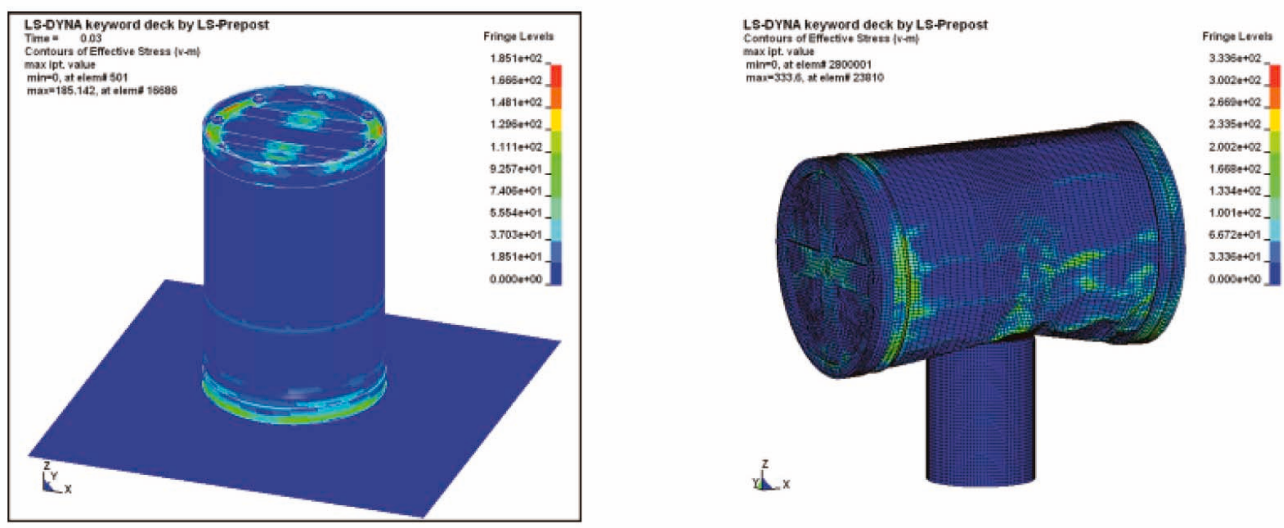

Fig. 2.1. Drop Analysis and Puncture Analysis Conducted after Drop Analysis

\section{DEVELOPMENT OF ANALYSIS METHODOLOGY TO EVALUATE CUMULATIVE DAMAGE}

IAEA regulations describe the hypothetical accident conditions of transport packages for radioactive materials. They also mandate safety assessments for transport packages under severe accident conditions. The hypothetical accident conditions include drop, puncture, fire, and water immersion conditions, and these conditions should be sequentially simulated $[1,2]$. For the real scale model test, a series of tests that simulate the severe conditions mentioned above can be performed sequentially. When a real scale model is not available, a scaled model is used for the drop, puncture, and water immersion tests and a sliced model for the fire test. However, in general, structural analyses to simulate hypothetical accident conditions are conducted independently of other conditions and do not consider the cumulative damage resulting from previous accident conditions. This is due to difficulties in reflecting the final results of the previous analysis on the current analysis. In this study, as the first step to consider cumulative damage, an analysis technology to perform a puncture analysis reflecting the final response field resulting from a drop analysis is proposed. The necessity and validity of the proposed analysis technology are evaluated by comparison with the results obtained by performing each analysis independently.

There are basically two methods available to perform an analysis to evaluate cumulative damage using FEMbased commercial software. The first is to utilize the function provided by the software. The second is to make an interface between two sequential analyses, such as receiving the data from the final status of the first analysis and sending these data to the second analysis as an initial status. The second method can be accomplished by manual operation and a user-specified code. The first method is available when using the LS-Dyna code. With the use of other codes, the first method cannot be applied. The availability of the first approach depends on whether the software utilizes a local coordinate system or a global coordinate system to address an object's response field. Therefore, the second method should be applied when the software does not provide this function. To develop and verify the analysis methodology to evaluate cumulative damage, a preliminary model and a cask model were utilized.

\subsection{Analysis and Test for Preliminary Model}

For the preliminary model, a simple canister was selected, since it would undergo plastic strain when dropped. The drop condition was decided to be a bottom down drop followed by a side puncture, as illustrated in Fig. 2.1. The cumulative damage was simulated by using the LSDyna explicit code. We can see the plastic deformation from the bottom down drop at the left side of Fig. 2.2. The right side feature in Fig. 2.2 represents the deformation after the side puncture without the bottom down drop. There is no deformation on the lower part of the model.

For the test, two simple canister structures were fabricated. The sequential drop tests were conducted for the first canister model with the same drop conditions as those of the analysis. A bottom down drop and a side puncture were performed sequentially with the first canister. For comparison, only the side puncture test without the bottom down drop test was performed with the second canister. We can see the cumulative deformation from the bottom down drop after the sequential drop test at the left side figure in Fig. 2.3. The strain history over the full test period is represented in Fig. 2.4. As seen in the figure, there are two jerks when the plastic strain occurs. These two jerks in the figure are the instances when the bottom drop and the side puncture test are performed, respectively. 

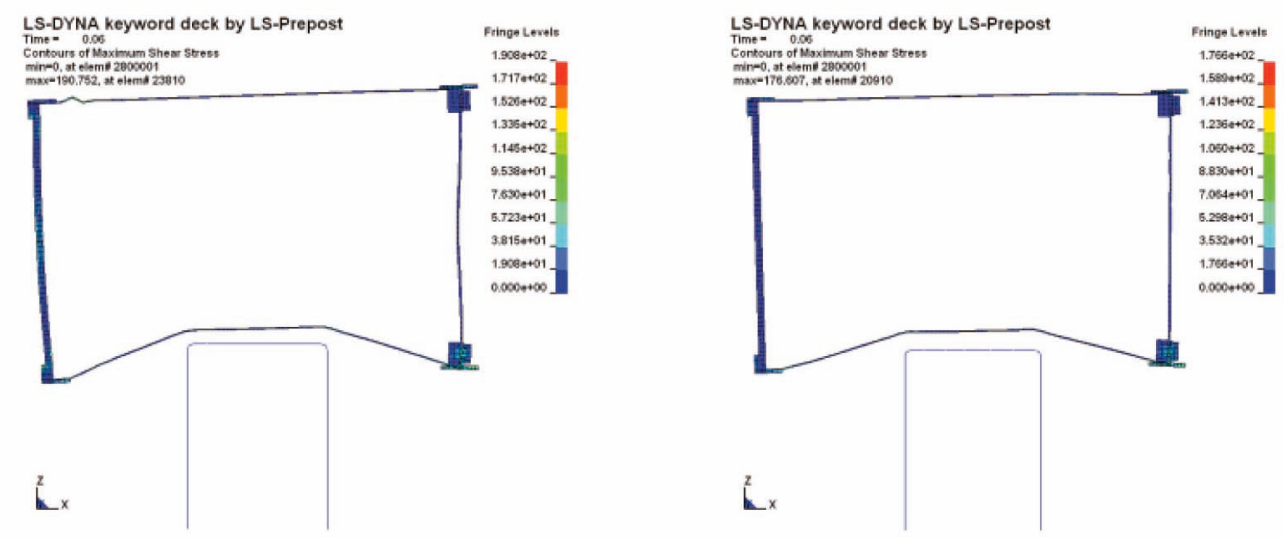

Fig. 2.2. Comparison of Deformations after the Sequentially Performed Drop and Puncture Analyses and after Puncture Analysis Only
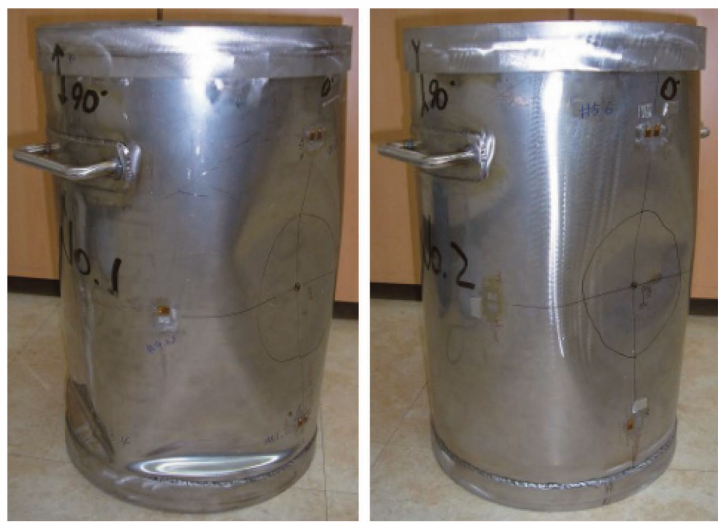

Fig. 2.3. Comparison of Deformations between the Sequential Drop Test and Puncture-only Test

\subsection{Analysis and Test for Cask Model}

For the evaluation of cumulative damage to a cask model, a dual purpose cask currently under development was utilized. The drop condition was decided to be a side drop followed by a side puncture. A sequential analysis was conducted by using the commercial software ABAQUS/Explicit 6.10 .2 code. The analysis is divided into three steps. The first step entails the side drop analysis. The second is setting the posture of the cask package after the side drop to provide the initial orientation for the side puncture analysis. The third is the side puncture analysis. For the second step, user specified code was utilized. This code was made by means of Intel Fortran. The time duration for the side drop is from $0.0 \mathrm{sec}$ to $0.02 \mathrm{sec}$, and the time duration for the side puncture is from $1.025 \mathrm{sec}$ to $1.075 \mathrm{sec}$. The time duration allocated for the preparation of the drop posture is from $0.02 \mathrm{sec}$ to $1.025 \mathrm{sec}$. The time

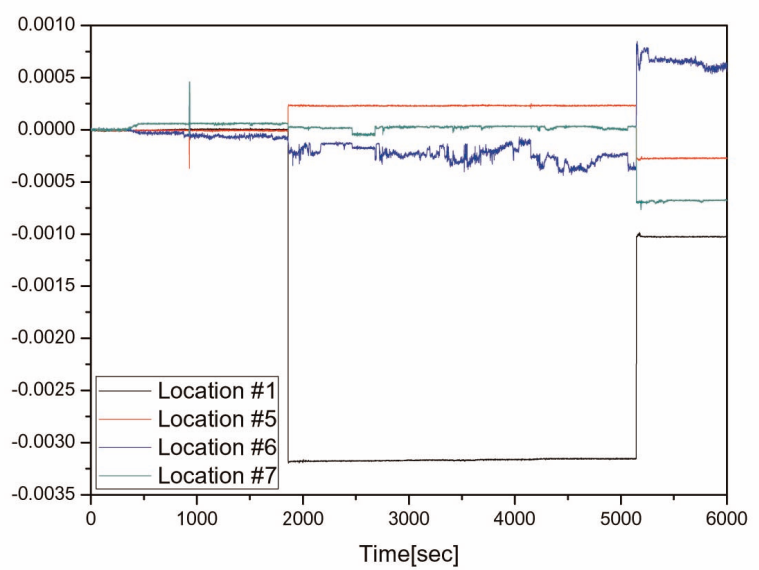

Fig. 2.4. Strain History during the Sequential Drop Test

duration for the second step is not a real time range but a time range determined arbitrarily by the user.

Strain histories at the specified location on the cask during the sequential analysis are represented in Fig. 2.5 and Fig. 2.6. The horizontal lines of the rear part in Fig. 2.5 and of the forepart in Fig. 2.6 indicate that the final status of the side drop analysis was applied as the initial status of the side drop analysis. In these figures, the actual plastic strains are relatively small. Two impact limiters are installed on the top and the bottom of the cask. Impact limiters absorb the impact energy. Therefore, the cumulative damage to the cask is estimated to be negligible or very small for the real cask system with the impact limiter. For comparison, each analysis, "side drop only" and "side puncture only", was also conducted. The strains of the drop part in the sequential analysis and the strains from "side drop only" have the same profiles and magnitudes. However, the strains of the puncture part in the sequential 
analysis and the strains from "side puncture only" have different profiles and magnitudes. This is due to the cumulative damage from the side drop condition, although it is estimated to be small.

For the test, a cask model was fabricated, as seen in Fig. 2.7. Sequential drop tests were conducted for the cask test model with the same drop conditions as those of the analysis. A side drop and a side puncture were performed sequentially. Very little plastic strain could be observed on the cask body since the impact limiters absorbed most of the impact energy. Strain histories are represented in Fig. 2.8 and Fig. 2.9. Considering that the analysis conditions cannot be actually same as those of test, the profile and the magnitude of strain histories in Fig. 2.8 and Fig. 2.9 are good coincident with those in Fig. 2.5 and Fig. 2.6.

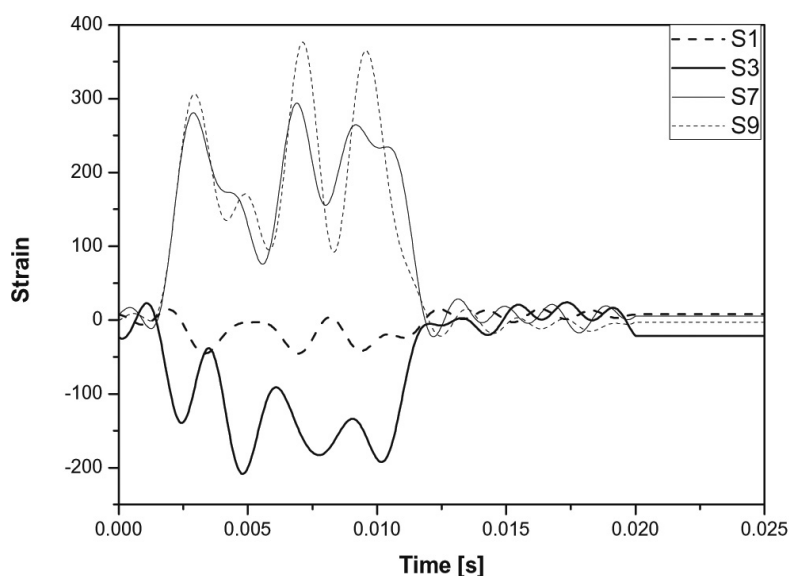

Fig. 2.5. Strain History during the Side Drop in Sequential Analysis (Surface of Cask)

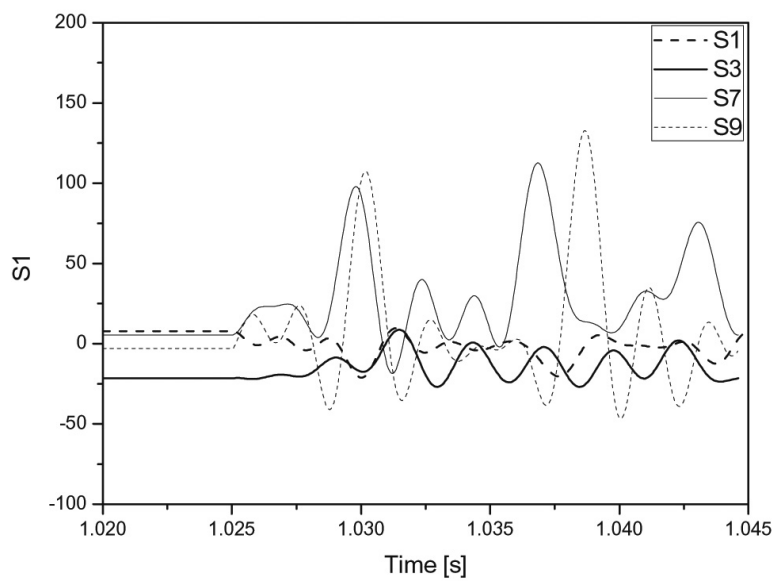

Fig. 2.6. Strain History during the Side Puncture in Sequential Analysis (Surface of Cask)

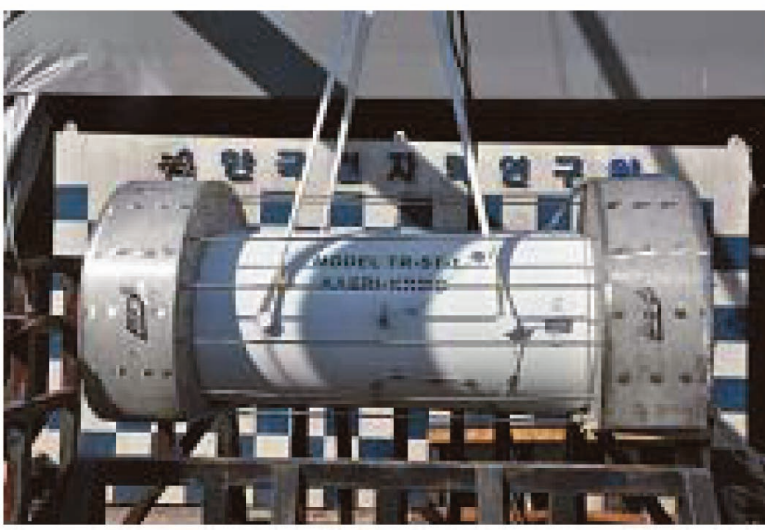

Fig. 2.7. Deformation of the Cask after the Side Drop Test

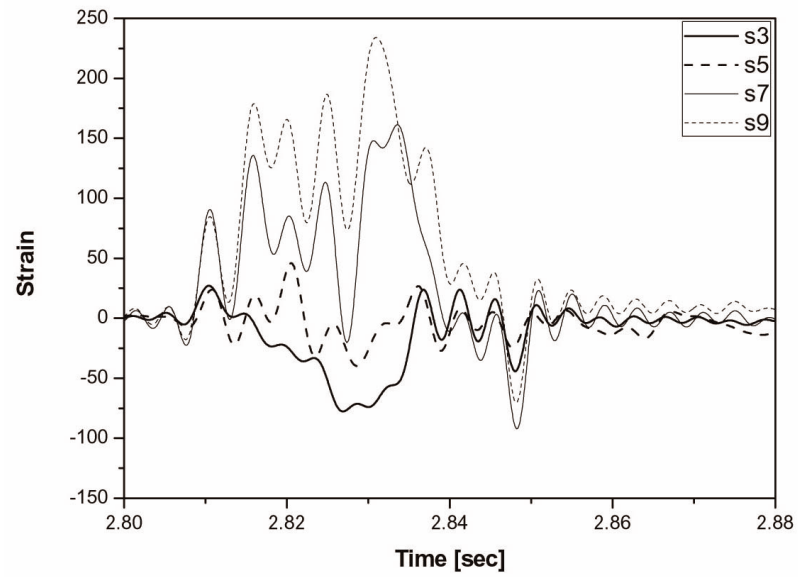

Fig. 2.8. Strain History during the Side Drop Test (Surface of Cask)

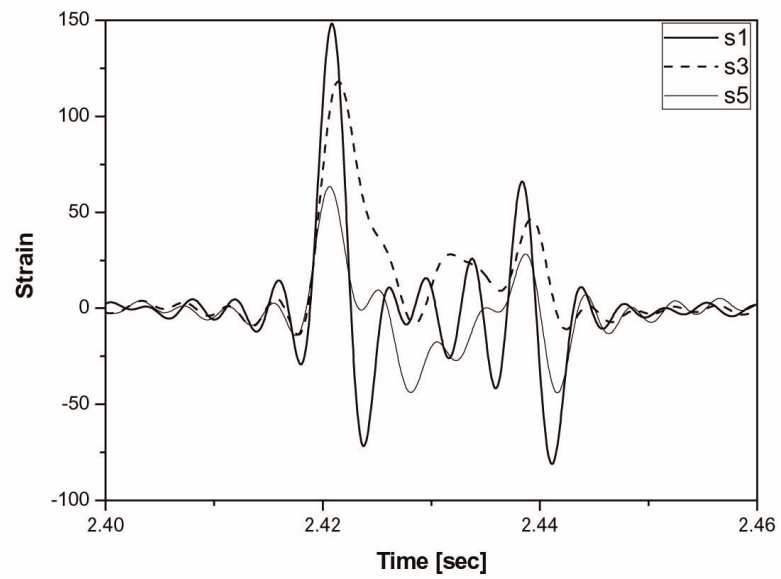

Fig. 2.9. Strain History during the Side Puncture Test (Surface of Cask) 


\section{SAFETY ASSESSMENT OF DUAL PURPOSE METAL CASK UNDER AIRCRAFT ENGINE CRASH}

Safety assessment against aircraft crashes is now considered an important issue in the design of facilities with hazardous materials such as nuclear power plants [3]. After the 9/11 terror attack, greater emphasis has been placed on the hypothetical situation of a targeted aircraft crash than on accidental cases. Recently, US NRC has revised 10 CFR 50.150 to include the requirements of a safety assessment against a targeted aircraft crash for the licensing of newly introduced nuclear power plants [4]. Many countries have performed safety assessments of spent nuclear fuel storage systems against a targeted aircraft crash using numerical simulations and tests $[5,6,7]$. In Korea, safety assessments of nuclear power plant under aircraft crash have been performed using numerical simulations, but fewer efforts have been reported on the safety assessments of spent nuclear storage systems. Moreover, no studies on safety tests and verification of the simulation results have been reported to date.

In this research, a safety assessment of a dual purpose metal cask that is currently under development by Korea Radioactive Waste Management Corporation (KRMC) is performed using numerical simulation and tests. A scenario of a targeted aircraft crash is established from a literature survey and impact conditions are derived from the scenario. Through a comparison of test results and the simulation results, the methodology used in the numerical simulation is verified. However, it should be noted that, since the cask is under development and the design is subject to change, the results of the assessment in this paper are tentative.

\subsection{Target System and Impact Conditions}

The spent nuclear fuel storage system considered in this research is a dual purpose metal cask that is under development by KRMC. It consists of a welded canister with a spent fuel basket and a metal cask with a lid. For ease of the simulation and tests, a simplified scale model of the original cask is designed, as presented in Fig. 3.1. The spent fuel basket is replaced by a dummy weight with the same mass and similar stiffness. The cask and the dummy weight are made of carbon steel A516 Gr. 70 and the canister is made of stainless steel A240 Type 304. The total weight of the $1 / 3$ scale model is $3578 \mathrm{~kg}$.

The aircraft crash scenario was set based on a NEI report. A large commercial aircraft B747 is selected and the impact velocity is set as $150 \mathrm{~m} / \mathrm{s}$, which is the measured velocity of the aircraft that struck the Pentagon on 9/11. Two impact orientations that are expected to produce the maximum damage to the containment boundary of the target system are considered in this study. In one case, the aircraft engine hits the upper part of the cask free-standing on a concrete pad (Case 1). In the other case, the aircraft engine hits the center of the cask lid perpendicularly (Case 2).

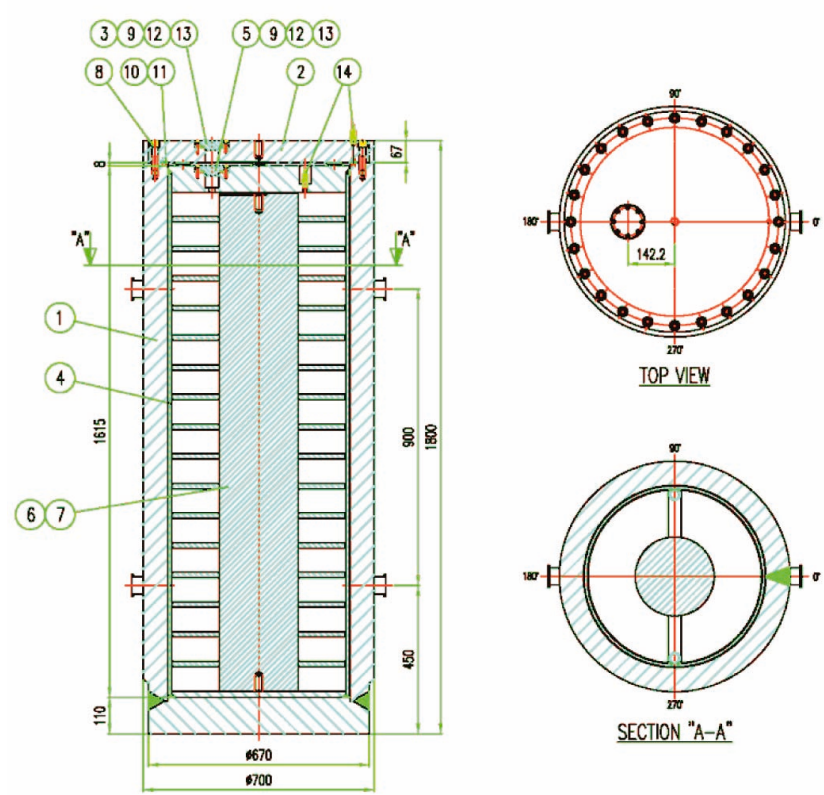

Fig. 3.1. Simplified Model of Dual Purpose Metal Cask

\subsection{Missile Design}

A simplified missile that simulates the engine of a B747 is designed. The engine weighs about 4.5 tons and the effective impact diameter is about $1.4 \mathrm{~m} \mathrm{[6].} \mathrm{The}$ impact load-time history curve proposed by K. Shirai et al [6] and the scale theory are utilized in the design of the simplified scale model of the engine, as seen in Fig. 3.2. The dimensions of the simplified missile are determined such that the load-time history of the missile impacting a rigid wall is as close to the reference curve as possible.

The simplified missile weighs $167 \mathrm{~kg}$ and its diameter is $355 \mathrm{~mm}$. It is made of carbon steel.

\subsection{Evaluation (Case 1)}

The numerical simulation for the Case 1 assessment is performed in two steps. Since the cask is not firmly supported but is free standing on a concrete pad, very dynamic behavior after the impact is expected. Thus, the first step simulation utilizes a simple model and lengthy duration to examine the impact behavior of the cask. This behavior would be very important when subsequent impacts of the cask are of concern, for example, in the case of collision with other casks. However, an evaluation considering the second and subsequent impacts is not covered in this paper. The simulation results show that the cask will gain significant angular velocity as well as a translational velocity in the direction of impact, as shown in Fig. 3.3. It is expected that the cask will land on the concrete pad after rising roughly $11 \mathrm{~m}$ in the air.

The second step of the evaluation utilizes a detailed 


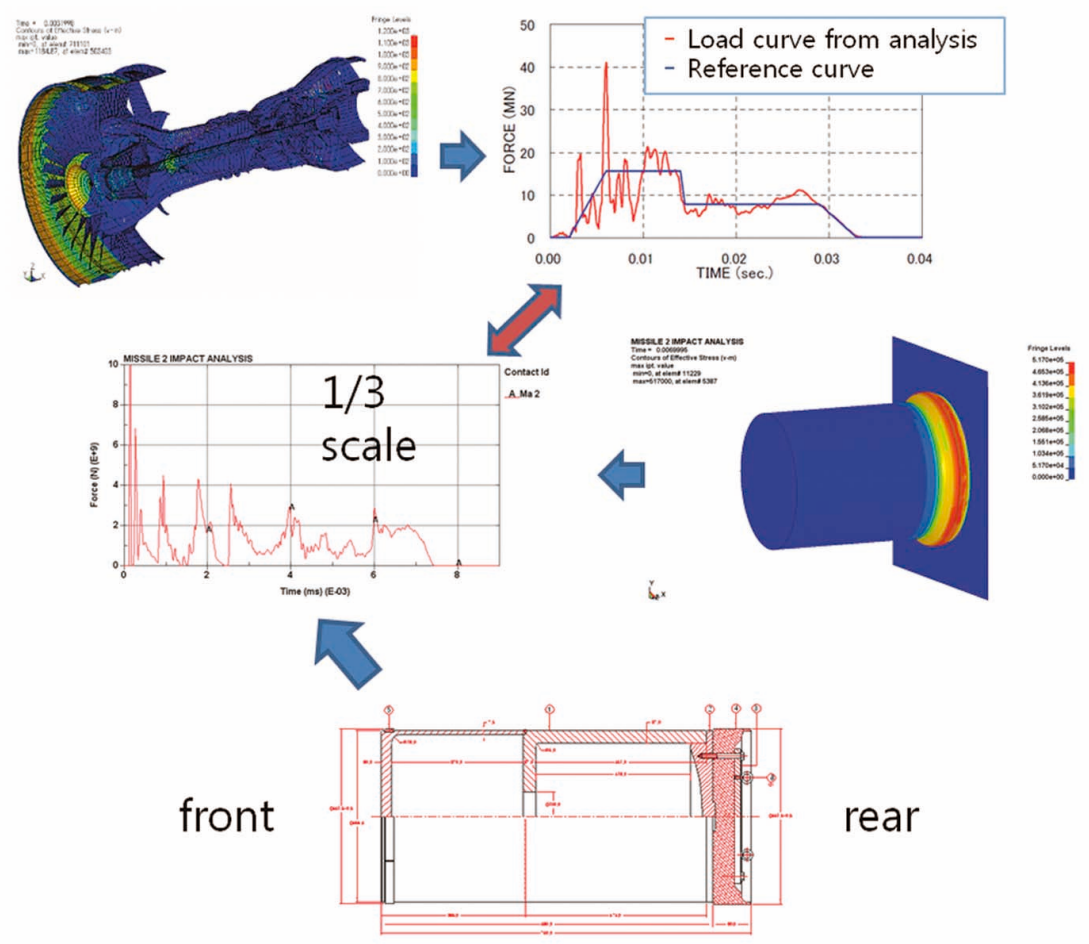

Fig. 3.2. Design of Simplified Missile

model to evaluate the structural response of the cask components upon the missile impact. The main focus of the evaluation is to examine the integrity of the containment of the cask. Dynamic material properties considering the strain rate effect are utilized in the simulation and bolt pretention is applied using dynamic relaxation. Fig 4 shows the stress contour at $3 \mathrm{~ms}$ after the impact and Fig. 3.5 is a diagram of the cask lid opening and sliding displacement. It is found that the cask suffers significant shear deformation in the lid-cask connection, but the lid opening remains in a rather small range; hence, we can conclude that the containment is not severely damaged in the first impact by the missile. The evaluation of containment integrity follows the procedure proposed in NUREG /CR-6672 by Sandia National Laboratory [8].

The test was performed in the testing site of the Agency of Defense Development (ADD). The missile was fired using a Counter Mass Gun (CMG) and the velocity of the missile was measured as $148 \mathrm{~m} / \mathrm{s}$. The behavior of cask after the impact is shown in Fig. 6. The first landing point of the cask is about $3.3 \mathrm{~m}$ far from the initial standing point, which is much smaller than the value $(11 \mathrm{~m})$ expected from the simulation. This discrepancy comes from the modeling of the concrete pad and the soil and will be covered in future research.

After the test, an assessment of the containment integrity of the cask and the canister was performed using a He leak tester. It was shown that the cask lid closure suffered extensive damage but the leak rate was kept under the allowable range. Thus, the conclusion from the simulation is verified with the test results.

\subsection{Evaluation (Case 2)}

The numerical simulation of the Case 2 assessment was carried out in one step using a detailed model. The support structure for the cask is replaced by a rigid wall at the bottom of the cask. The simulation results show that the cask lid suffers a significant amount of plastic deformation and it also causes a large impact force on the upper part of the canister, as shown in Fig. 3.7.

Due to the deformation of the cask lid, the lid bolts suffer large bending moments, causing the bolts to bend inwards by about 0.5 degree. Examining the lid opening and the sliding displacement history (Fig. 3.9), it is found that the lid opening is larger than the allowable range and breaching of the containment boundary is highly probable. Stress at the canister weld zone is also significant, but an evaluation of the canister is not covered in this paper.

The test was performed in the ADD testing site using CMG as in Case 1 evaluation. The missile velocity was measured as $155 \mathrm{~m} / \mathrm{s}$ and the behavior after the impact is shown in Fig. 3.8. 


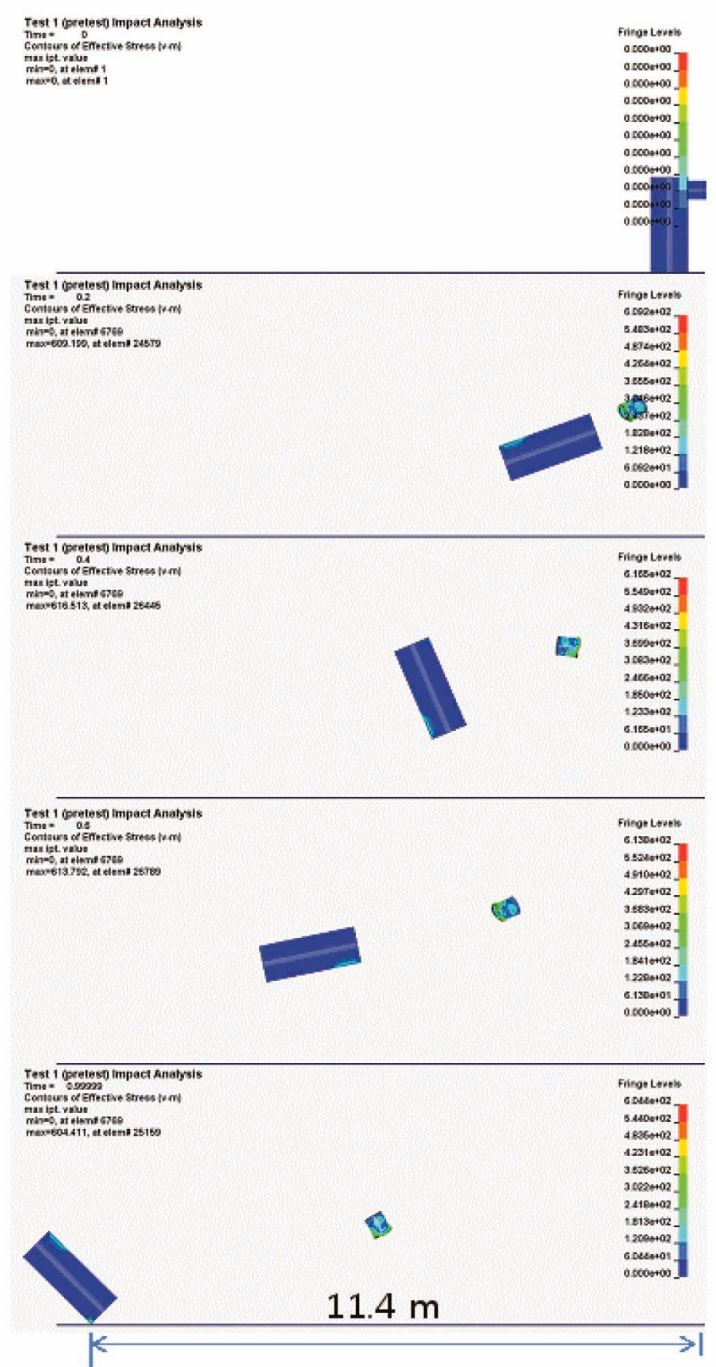

Fig. 3.3. Dynamic Behavior after Impact

Time $=0.0010999$

etive Stress (v-m)

$\max$ ipt. value
$\min m 0$, at elem"

$\max =1058.09$, at elem: 310697

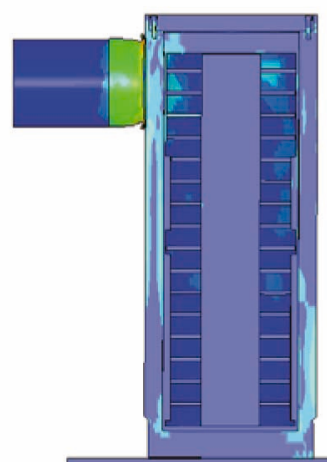

Fig. 3.4. Stress Contour (@3ms after Impact)

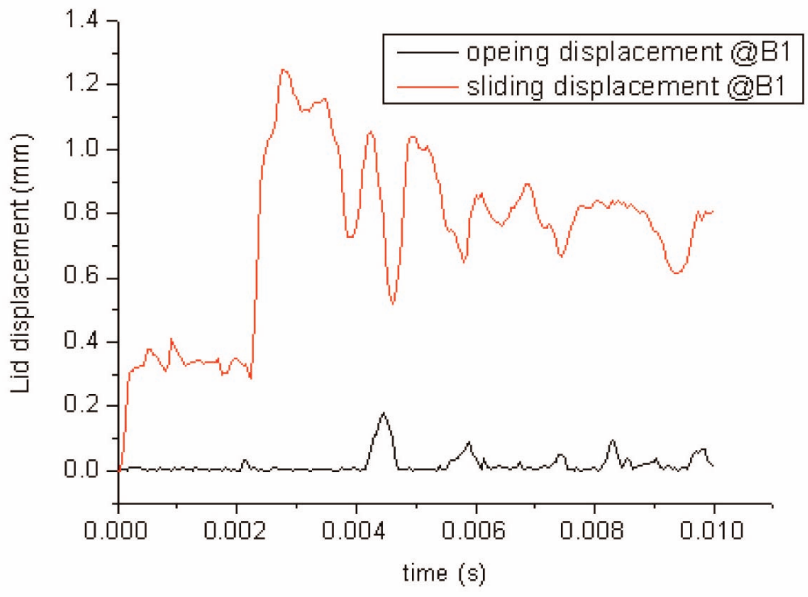

Fig. 3.5. Lid Opening, Sliding Displacement History

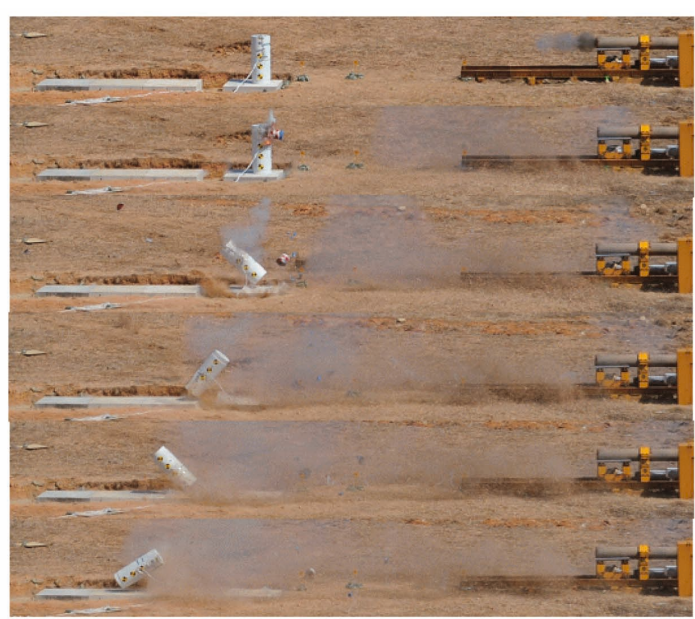

Fig. 3.6. Cask Behavior after Impact

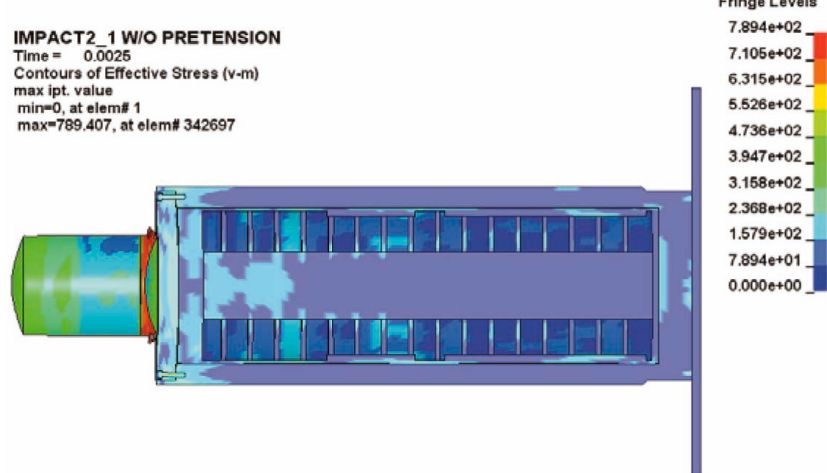

Fig. 3.7. Stress Contour (@2.5 ms after Impact) 


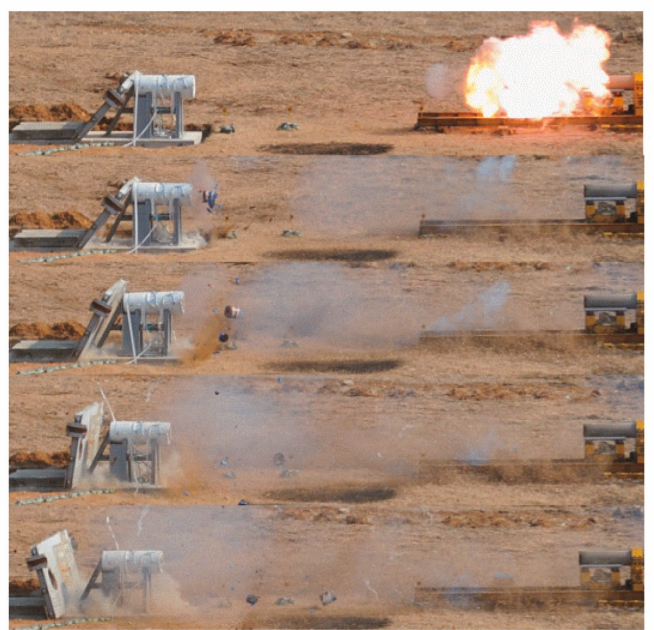

Fig. 3.8. Horizontal Impact

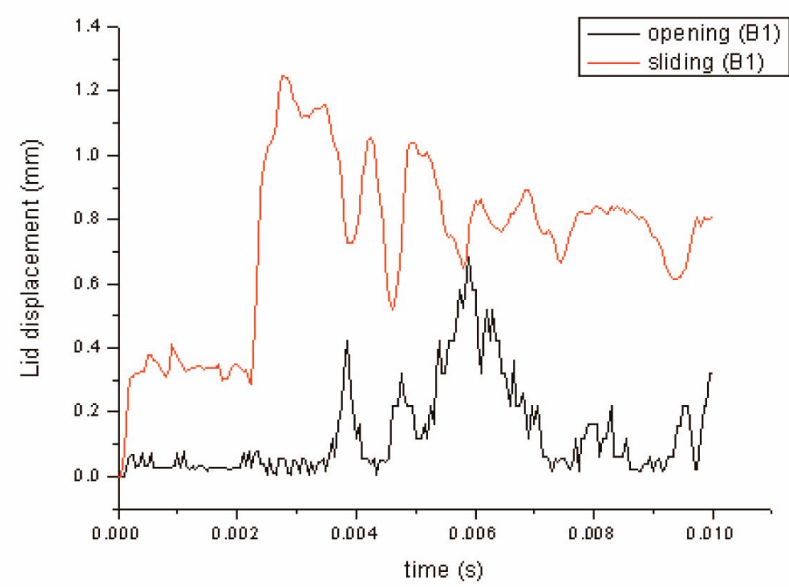

Fig. 3.9. Lid opening, Sliding Displacement History (Case 2)

It is seen that the support structure for the cask is detached from the concrete pad due to the impact shock and is pushed backward about $40 \mathrm{~cm}$. It should absorb some impact energy and may mitigate the severity of impact results at the cask side. After the impact, the cask lid was deformed into a very similar shape to that predicted by the simulation, and the bolts were bent inward up to 1.5 degrees. In the He leak test, the cask showed a significant level of leakage, thus indicating that the containment boundary is breached due to the missile impact. It is thus shown that the test results agree well with the simulation results.
The impact condition in the Case 2 evaluation is rather unrealistic, since the impact orientation is almost impossible. However, the conclusion of this evaluation is that the current design version of the dual purpose metal cask cannot survive under a $150 \mathrm{~m} / \mathrm{s}$ impact of an aircraft engine perpendicular to the center of the lid.

\section{DISCUSSION AND CONCLUSIONS}

An analysis methodology to simulate the cumulative damage from a drop condition to a puncture condition was proposed. Analyses and tests with a preliminary test model and with a cask model were conducted. By the analyses and tests with the preliminary model, the method to evaluate the cumulative damage was verified. In the case of the cask model, we found that the cask with an impact limiter undergoes small cumulative damage from the drop condition. The results could thus appear to be satisfactory if we do not consider the cumulative damage. However, the cumulative damage must be considered in the case of a canister or cask without impact limiter and in the case of a drop condition where the impact limiter fails to function properly.

A procedure for a safety assessment using a numerical simulation for an aircraft engine crash into a spent nuclear fuel storage systems is proposed. The simulation results show very good agreement with the test results. It is noted that this is the first study conducted in Korea involving tests considering a simulated aircraft crash. The studies described above will be followed by further research led by KRMC.

\section{REFERENCES}

[1] Tsu-te Wu, et al, "Dynamic Analysis of Hanford Unirradiated Fuel Package Subjected to Sequential Lateral Loads in Hypothetical Accident Conditions", PVP 2008-61564.

[2] J. M. Jordan, "Finite Element Analysis of Bulk Tritium Shipping Package", INMM.

[3] DOE standard DOE-STD-3014-2006, "Accident analysis for aircraft crash into hazardous facilities," US DOE: 2006.

[4] US NRC, 10 CFR 50.150 Aircraft impact assessment, 2009

[5] NEI, "Deterring terrorism: Aircraft crash impact analyses demonstrate nuclear power plant's structural strength," NEI, 2002

[6] K Shirai et al. "Safety analysis of dual purpose metal cask subject to impulsive load due to aircraft engine crash," Journal of Power and Energy Systems, Vol. 3, pp. 72-82

[7] J Stepan et al. "Consequences of the large commercial aircraft crash into the interim spent fuel storage facility," Proceedings of SMiRT 18, Beijing, China, 2005

[ 8 ] NUREG/CR-6672, Reexamination of spent fuel shipment risk estimates, Sandia National Laboratory, 2004 